\title{
Preliminary evaluation of organic carbon sedimentation rates in Asian mangrove coastal ecosystems estimated by ${ }^{210} \mathrm{~Pb}$ chronology
}

\author{
Y. Tateda ${ }^{1}$, D.D. Nhan ${ }^{2}$, G. Wattayakorn ${ }^{3}$ and H. Toriumi ${ }^{4}$ \\ ${ }^{1}$ Ecosystem Analysis Group, Biological Environment Sector, Environmental Science \\ Research Laboratory, CRIEPI., 270-1194 Abiko, Chiba, Japan \\ ${ }^{2}$ Center for Radiation Protection and Environment Monitoring, INST., PO Box 5T-160, Hoang \\ Quoc Viet, Hanoi, Virtnam \\ ${ }^{3}$ Department of Marine Science, Chulalongkorn University, 10330 Bangkok, Thailand \\ ${ }^{4}$ Technology Development Dept. ENAA., 105-0003 Minato-ku, Tokyo, Japan
}

\begin{abstract}
The organic carbon accumulation rate in mangrove ecosystem was reported to be important sink of carbon as well as that in boreal peat accumulation. For the estimation of 10 years scale organic carbon accumulation rates at mangrove plantation coastal area, the ${ }^{210} \mathrm{~Pb}$ is expected to be suitable for decades scale estimation by its half-life, though it has possibility of bio-/physical- turbation effect in applying ${ }^{210} \mathrm{~Pb}$ chronology, especially in Asian mangrove ecosystem where the anthropogenic physical turbation by coastal fishery is vigorous. We studied the organic carbon and ${ }^{210} \mathrm{~Pb}$ accumulation rates in subtropical mangrove coastal ecosystems in Japan, Vietnam and Thailand to remove the effect of bio-, anthropogenic turbation on organic carbon accumulation. We finally concluded that ${ }^{210} \mathrm{~Pb}$ was applicable to estimate organic carbon accumulation rates in these ecosystems. The measured organic carbon accumulation rates using ${ }^{210} \mathrm{~Pb}$ in mangrove coastal ecosystems of Japan, Vietnam and Thailand were $0.22-6.0 \mathrm{t}-\mathrm{C} \mathrm{ha}{ }^{-1} \mathrm{y}^{-1}$.
\end{abstract}

\section{INTRODUCTION}

Organic carbon balance estimation of mangrove coastal ecosystem is important for understanding of Asian coastal carbon budget/flux calculation in global carbon cycle modelling which is powerful tool for the prediction of future greenhouse gas effect and evaluation of countermeasure preference. Especially, the organic carbon accumulation rate in mangrove ecosystem was reported to be important sink of carbon as well as that in boreal peat accumulation [1]. For the estimation of $10^{3}$ years scale organic carbon accumulation rates in mangrove coastal ecosystems, ${ }^{14} \mathrm{C}$ was used as long-term chronological tracer, being useful in pristine mangrove forest reserve area. While in case of mangrove plantation area, the ${ }^{210} \mathrm{~Pb}$ is expected to be suitable for decades scale estimation by its half-life [2]. However, it has possibility of bio-/physical- turbation effect in applying ${ }^{210} \mathrm{~Pb}$ chronology, especially in Asian mangrove ecosystem where the anthropogenic physical turbation by coastal fishery is vigorous. In this paper, we studied the organic carbon and ${ }^{210} \mathrm{~Pb}$ accumulation rates in subtropical mangrove coastal ecosystems in Japan, Vietnam and Thailand by removing turbation effects on organic carbon accumulation. 


\section{METHODS}

\subsection{Study area}

Mangrove coastal areas of Fukido, Ishigaki, Japan (N, E), DaLoc, ThanHoa, Vietnam (N, E) and Trat, Thailand (N, E) are approximately 5ha, 150 ha and 500 ha, respectively. Mangrove forests expand to seaward $200 \mathrm{~m}, 400 \mathrm{~m}$ and $500 \mathrm{~m}$ at Fukido, DaLoc and Trat, respectively. Each mangrove areas are in the intertidal zone and are covered by coastal water during high tide (minimum water depth $1 \mathrm{~m}$ ) while are exposed to air during low tide. Salinity ranges of intruded coastal waters were $10-30$ permillage at every study sites except heavy rain period. Fukido mangrove coastal area has a small river while mangrove coastal areas of DaLoc and Trat has high river water discharge especially during rainy seasons.

\subsection{Sampling and analysis}

Sediment cores of $6-20 \mathrm{~cm}$ diameter, $100 \mathrm{~cm}$ length were sampled at sampling points along the vertical lines from the shore side forest edge, the intertidal forest area, to the terrestrial forest edge in each mangrove coastal area. Cores were frozen after sampling on the spot. After transport to laboratory, cores were sectioned sieved by particle sizes. Organic carbon concentrations were analyzed by SHIMAZU NC-1000 after removal of calcium carbonate by exposure to hydrochloric acid vapour. ${ }^{210} \mathrm{~Pb}$ in samples were analyzed by direct measurement by $\gamma$-spectrometery (Canberra equipped with a HPGe detector, $40 \mathrm{keV}$ to $5 \mathrm{MeV}$ ) and was also measured by equilibrated ${ }^{210}$ Po plated on silver disk followed by $\alpha$-spectrometery (SEIKO EG \& G). The activity of ${ }^{226} \mathrm{Ra}$ used to estimate the supported ${ }^{210} \mathrm{~Pb}$ determined by $295 \mathrm{keV}$ and $352 \mathrm{keV} \gamma$-rays emitted by its daughters ${ }^{214} \mathrm{~Pb}$ and by $609 \mathrm{keV} \gamma$-rays emitted by ${ }^{214} \mathrm{Bi}$.

\section{RESULTS AND DISCUSSION}

\subsection{Organic carbon content in mangrove sediment}

Typical organic carbon content in $<38 \mu \mathrm{m}$ sediment particle and weight $\%$ of $<38 \mu \mathrm{m}$ sediment particle to total sediment sections at mangrove area of 3 study sites are shown in Figure 1 and 2. Weight $\%$ of $<38 \mu \mathrm{m}$ size sediment particles dominate in mangrove sediment at each study sites. Organic carbon contents in $<38 \mu \mathrm{m}$ sediment at Fukido, Ishigaki, Japan were 5\% those distributed 50-80\% in total organic carbon in sediment sections as shown in Figure 1. In mangrove sediment at DaLoc ThanHoa, Vietnam, 98 weight $\%$ of sediments were $<38 \mu \mathrm{m}$ particles size, and organic contents were approximately $2 \%$, indicating that most of organic carbon was contained in $<38 \mu \mathrm{m}$ sediment particles. Similar result was obtained at mangrove sediment at Trat, Thailand, while organic carbon content increased in terrestrial edge of forest and weight $\%$ of $<38 \mu \mathrm{m}$ particles size decreased. However, the most of organic carbon was still contained in $<38 \mu \mathrm{m}$ sediment particles.

The results indicated that supplied organic carbon as litter from tree or from root system is quickly subdivided by micro-organism in sediment. This subdivision makes refractory organic carbon as $<38 \mu \mathrm{m}$ particle size in mangrove sediment in 3 study sites.

\section{$3.2{ }^{210} \mathrm{~Pb}$ content in mangrove sediment}

${ }^{210} \mathrm{~Pb}$ content in particle size of $<38 \mu \mathrm{m}$ in sampling points at 3 study sites are shown in Figure 3 .

${ }^{210} \mathrm{~Pb}$ concentrations in mangrove sediment cores at each study sites were mostly decreased exponentially at depth. In mangrove sediment of Fukido, Ishigaki, Japan, ${ }^{210} \mathrm{~Pb}$ concentrations in surface sediment were in the range of $0.1-0.5 \mathrm{~Bq} \mathrm{~g}^{-1}$ dry sediment, and were low in shore-side mangrove sediment. ${ }^{210} \mathrm{~Pb}$ content in particle size of $<38 \mu \mathrm{m}$ in sampling points at DaLoc, Than Hoa, 
Vietnam mangrove area demonstrates that ${ }^{210} \mathrm{~Pb}$ concentrations in surface sediment were approximately $0.07 \mathrm{~Bq} \mathrm{~g}^{-1}$ dry sediment and were not so significantly different in mangrove area, while those at Trat, Thailand were in the range of $0.04-0.1 \mathrm{~Bq} \mathrm{~g}^{-1}$ dry sediment and high concentration in surface sediment at terrestrial edge of mangrove sediment area.
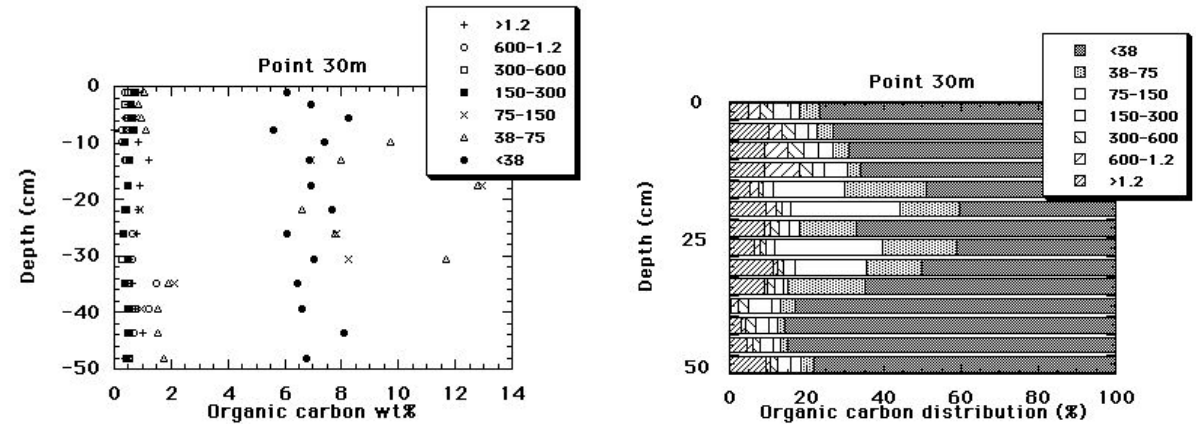

Figure 1. Organic carbon content and distribution ratio of different particle size at sampling point at 30m distant from mangrove coastal edge in Fukido, Ishigaki, Japan.
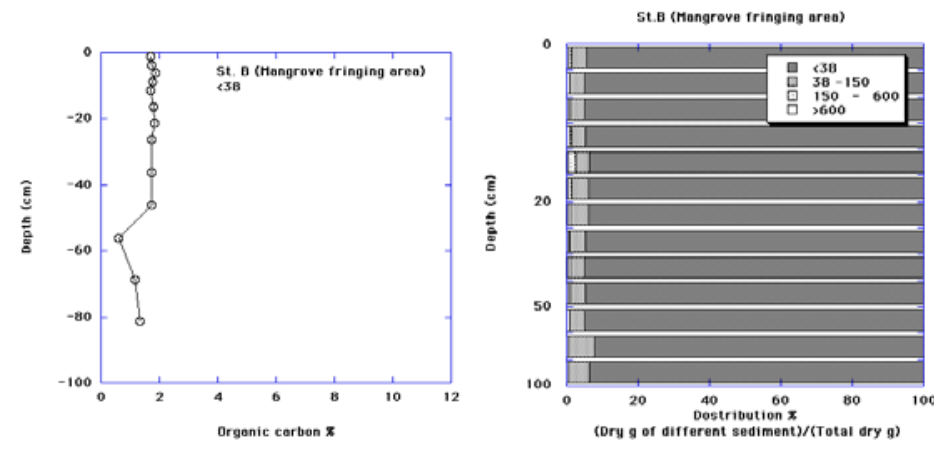

a)
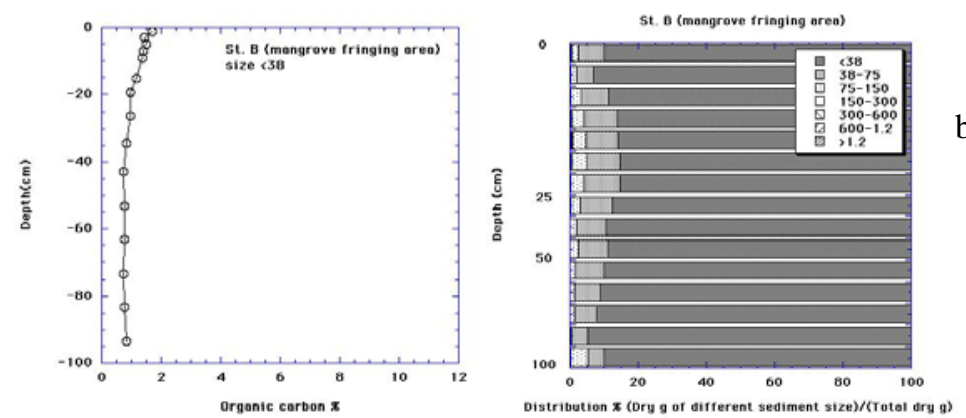

Figure 2. Organic carbon content and distribution ratio of different particle size at sampling point at $10 \mathrm{~m}$ distant from mangrove coastal edge in DaLoc, Vietnam (a) and Trat, Thiland (b).

In some sediment cores, surface sediment were disturbed, and some signal of downward transport of surface sediment to deeper sediment were observed, however uniform bioturbation layer was not so significantly obvious by ${ }^{210} \mathrm{~Pb}$ vertical profiles. Thus the organic carbon and sediment particles may be lost from sediment floor by biological upward sediment transport activity, especially in mangrove area at Fukido, Ishigaki, Japan, while those effect could not be so significant in DaLoc, ThanHoa, Vietnam and Trat, Thailand. Anthropogenic physical disturbed core can be avoidable by sampling planning. By removing signal of downward transport of surface sediment to deeper layer, the 
1)
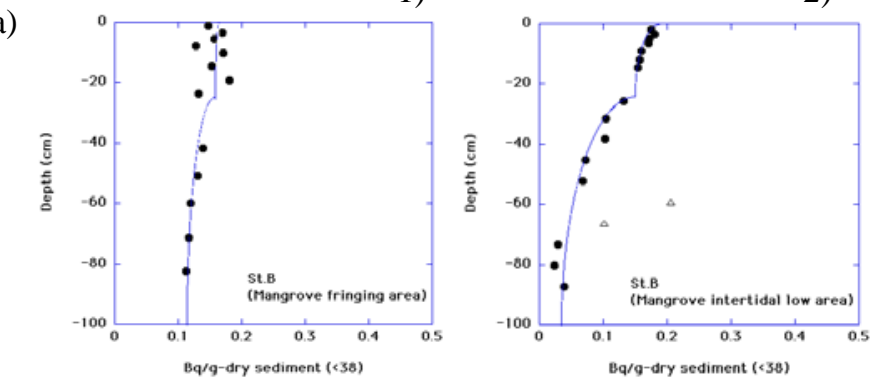

3)

4)

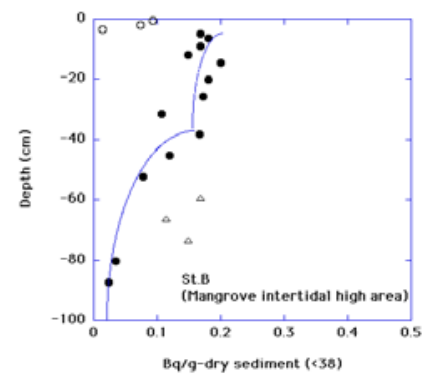

1)

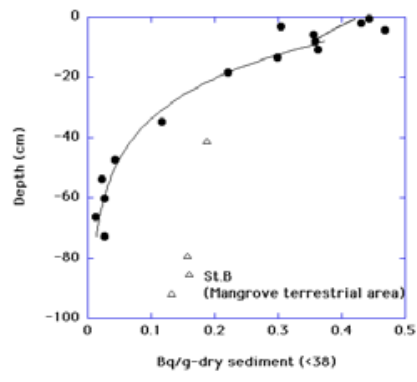

2)

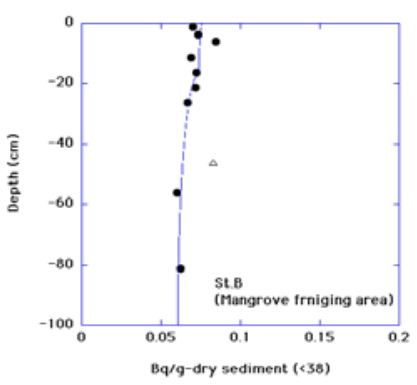

c)
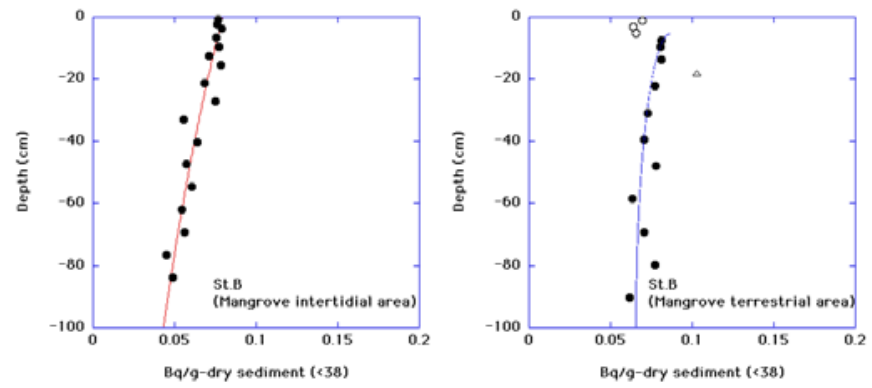

1)

2)

3)
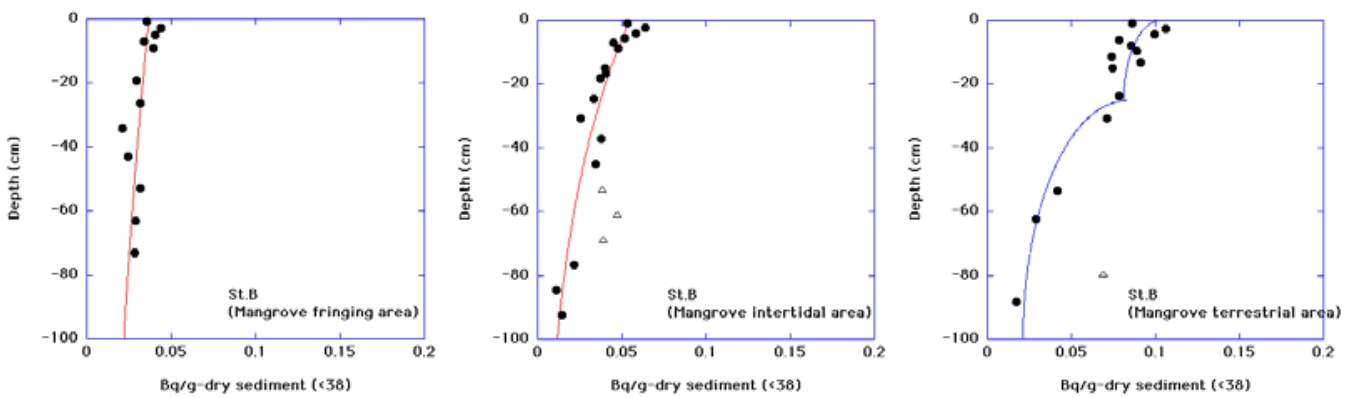

Figure 3. ${ }^{210} \mathrm{~Pb}$ content in particle size of $<38$ in sampling points at $30 \mathrm{~m}(1), 60 \mathrm{~m}(2), 90 \mathrm{~m}(3), 120 \mathrm{~m}(4)$ distant from mangrove shore-side edge in Fukido, Ishigaki, Japan (a), 10m(1), 100m(2), 200m(3) distant from mangrove shore-side edge in DaLoc, ThanHoa, Vietnam (b), at 10m(1), 70m(2), 140m(3). 
a)

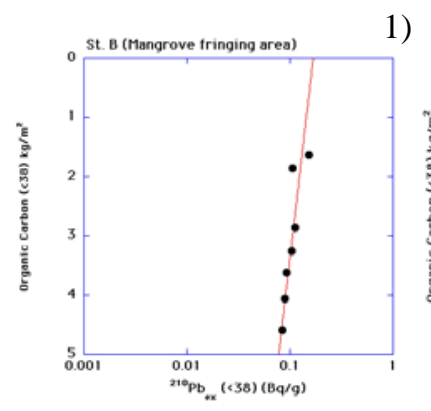

1)

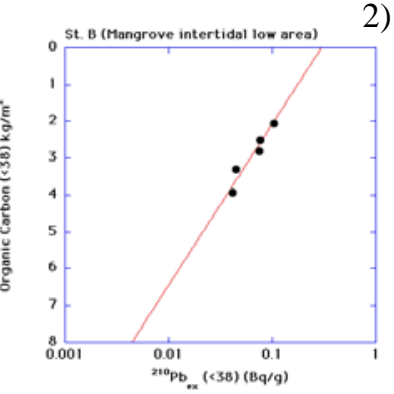

2)

3)

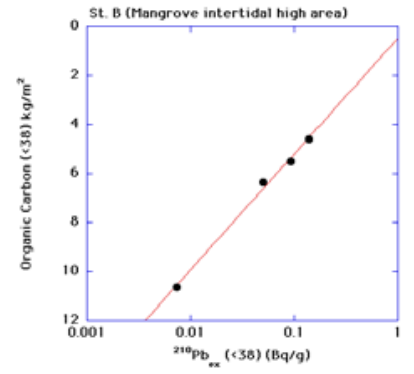

4)

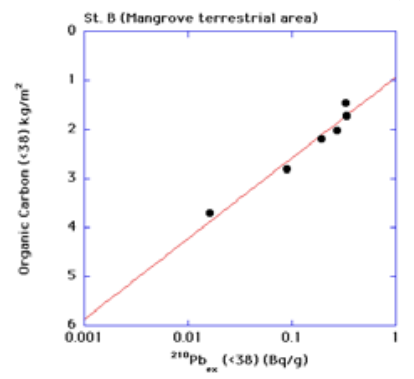

b)

1)

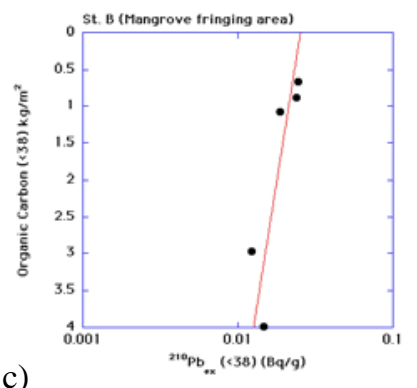

1)

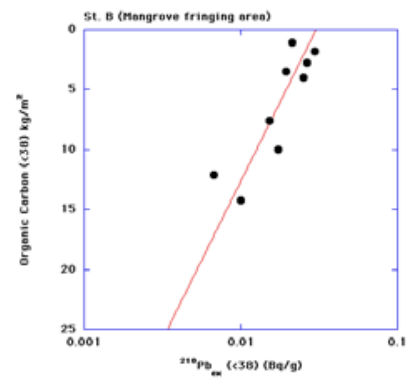

2)

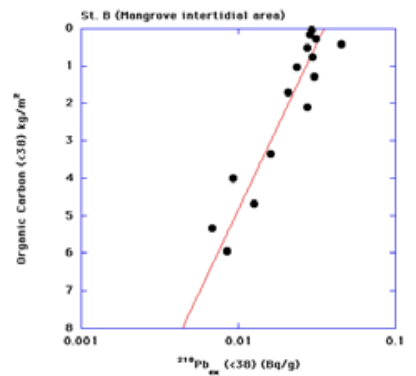

2)

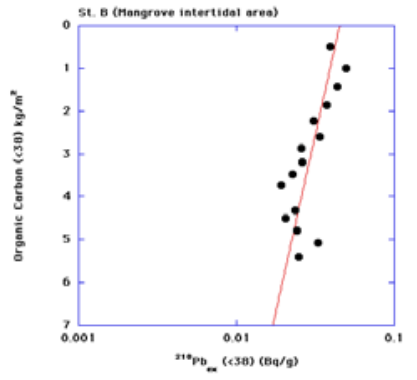

3)

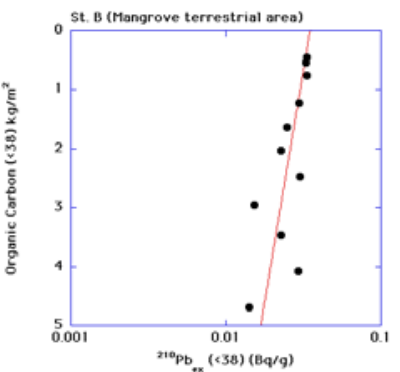

3)

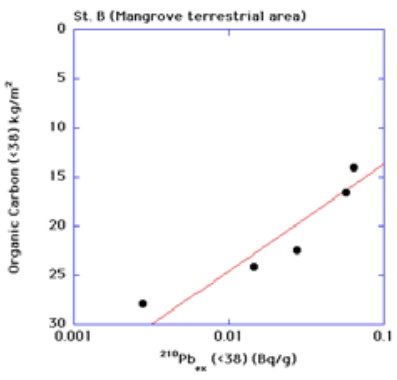

Figure 4. Relation of organic carbon particle accumulation and ${ }^{210} \mathrm{~Pb}_{\mathrm{ex}}$ content in particle size of $<38 \mu \mathrm{m}$ in sampling points at $30 \mathrm{~m}(1), 60 \mathrm{~m}(2), 90 \mathrm{~m}(3), 120 \mathrm{~m}(4)$ distant from mangrove shore-side edge in Fukido, Ishigaki, Japan (a), 10m(1), 100m(2), 200m(3) distant from mangrove shore-side edge in DaLoc, ThanHoa, Vietnam (b), at $10 \mathrm{~m}(1), 70 \mathrm{~m}(2), 140 \mathrm{~m}(3)$ distant from mangrove shore-side edge in Trat Thailand (c) mangrove area. 
observed ${ }^{210} \mathrm{~Pb}$ vertical profiles in sediment cores can be used for ${ }^{210} \mathrm{~Pb}$ chronology to estimate organic carbon accumulation rate in mangrove sediment.

\subsection{Preliminary evaluation of organic carbon sedimentation rate estimated by ${ }^{210} \mathrm{~Pb}_{\mathrm{ex}}$ deposition rate}

According to the observed 1) high organic carbon content in $<38 \mu \mathrm{m}$ size, 2) prevailed weight \% of $<38 \mu \mathrm{m}$ particle size, 3) high ${ }^{210} \mathrm{~Pb}$ concentrations in $<38 \mu \mathrm{m}$ size sediment, 4) ${ }^{210} \mathrm{~Pb}_{\text {ex }}$ depth profile logically reflects decay year after sedimentation on surface by removing bioturbation signal, we used the data of organic carbon and ${ }^{210} \mathrm{~Pb}_{\text {ex }}$ in $<38 \mu \mathrm{m}$ particle size in the estimation. Relation of organic carbon accumulation amount and ${ }^{210} \mathrm{~Pb}_{\mathrm{ex}}$ content in particle size of $<38 \mu \mathrm{m}$ at each sections at sampled cores of Fukido, Ishigaki, Japan, DaLoc, Than Hoa, Vietnam, Trat Thailand mangrove area are shown in Figure 4. Using ${ }^{210} \mathrm{~Pb}$ half-life (22.3 years), organic carbon integrated weight as shown in Figure 4, organic carbon sedimentation rates in each mangrove coastal study sites were calculated and shown in Table 1 with derived ${ }^{210} \mathrm{~Pb}_{\text {ex }}$ deposition on mangrove surface sediment and reported atmospheric ${ }^{210} \mathrm{~Pb}$ deposition at the area of same latitudes [3].

Table 1. Organic carbon sedimentation rates, derived ${ }^{210} \mathrm{~Pb}_{\mathrm{ex}}$ deposition by core data on each mangrove study sites and reported atmospheric ${ }^{210} \mathrm{~Pb}$ deposition at the area of same latitudes.

\begin{tabular}{|c|c|c|c|}
\hline \multicolumn{4}{|c|}{$\begin{array}{l}\text { Study sites Fukido, Ishiaki DaLoc,Than Hoa Trat } \\
\text { Location Japan (N24, E124) Vitnam (N20,E106) Thailand (N12,E102) }\end{array}$} \\
\hline $\begin{array}{l}\text { Organic carbon sedimentation rate } \\
\left(<38 \mu \mathrm{m}, \mathrm{kg}-\mathrm{C} / \mathrm{m}^{2} / \text { year }\right)\end{array}$ & $0.022 \sim 0.23$ & $0.12 \sim 0.18$ & $0.10 \sim 0.60$ \\
\hline $\begin{array}{l}{ }^{210} \mathrm{~Pb}_{\mathrm{ex}} \text { sedimentation rate } \\
\qquad\left(<38 \mu \mathrm{m}, \mathrm{Bq} / \mathrm{m}^{2} / \text { year }\right)\end{array}$ & $300 \sim 1300$ & $180 \sim 320$ & $140 \sim 260$ \\
\hline $\begin{array}{l}\text { Atmospheric }{ }^{210} \mathrm{~Pb} \text { deposition } \\
\qquad\left(\mathrm{Bq} / \mathrm{m}^{2} / \text { year }\right)\end{array}$ & $100 \sim 350$ & $90 \sim 250$ & $90 \sim 150$ \\
\hline
\end{tabular}

The measured organic carbon accumulation rates using ${ }^{210} \mathrm{~Pb}$ in mangrove coastal ecosystems of Japan, Vietnam and Thailand were the highest at Trat, Thailand being $1.0-6.0 \mathrm{t}-\mathrm{C} \mathrm{ha}{ }^{-1} \mathrm{y}^{-1}$, followed by $1.2-1.8 \mathrm{t}-\mathrm{C} \mathrm{ha}{ }^{-1} \mathrm{y}^{-1}$ at DaLoc Than Hoa, Vietnam, and the lowest at Fukido, Ishigaki, Japan, $0.22-2.3 \mathrm{t}-\mathrm{C} \mathrm{ha}{ }^{-1} \mathrm{y}^{-1}$. Derived ${ }^{210} \mathrm{~Pb}$ deposition rate on mangrove area were always larger than reported atmospheric ${ }^{210} \mathrm{~Pb}$ deposition at the area of same latitude, indicating that the mangrove area is the sink of ${ }^{210} \mathrm{~Pb}$ at coastal ecosystems not only from atmospheric ${ }^{210} \mathrm{~Pb}$ deposition but also from ${ }^{210} \mathrm{~Pb}$ supplied from coastal water.

\section{Acknowledgements}

This work was partly supported by the research of $\mathrm{CO}_{2}$ sequestration and collection technology funded by New Energy and Industrial Technology Development Organization and Research Institute of Innovative Technology fir the Earth.

\section{References}

[1] Ong, J. E. "Mangroves - a carbon source and sink.", Chemosphere. 27 (1993) 1097 - 1107.

[2] Tateda Y., "Organic carbon supply and accumulation in mangrove coastal sediment ", Nippon Suisan Gakkaishi. 685 (2002) 736-737.

[3] Preiss N., Melieres, M-A., and Pourchet, M., "A compilation of data on lead 210 concentration in surface air and fluxes at the air-surface and water-sediment interfaces", J. Geophysical. Res. 101 D22 (1996) 28,847-28,862. 